\title{
Time-resolved step scan FTIR spectroscopy and DFT investigation on triplet formation in peridinin-chlorophyll- $a$-protein from Amphidinium carterae at low temperature
}

\author{
Alberto Mezzetti ${ }^{\mathrm{a}, \mathrm{b}, *}$ and Riccardo Spezia ${ }^{\mathrm{c}}$ \\ ${ }^{\text {a }}$ Laboratoire de Spectrochimie Infrarouge et Raman UMR CNRS 8516, Université de Sciences \\ et Technologies de Lille, 59655 Villeneuve d'Ascq, France \\ ${ }^{\mathrm{b}}$ Dipartimento di Scienze Chimiche, Università di Padova, 35131 Padova, Italy \\ ${ }^{\mathrm{c}}$ Laboratoire Analyse et Modélisation pour la Biologie et l'Environnement UMR CNRS 8587, \\ Université d'Évry-val-d'Essonne, 91025 Evry, France
}

\begin{abstract}
We have used time-resolved step-scan FTIR spectroscopy to investigate the process of triplet formation in the peridinin-chlorophyll- $a$-protein (PCP) at $100 \mathrm{~K}$. Results have led to the identification of possible marker bands for peridinin (Per) and ${ }^{3}$ Per. Band assignment has been carried out performing a DFT investigation on Per, ${ }^{3}$ Per and on model molecules. The main spectral feature is a couple of bands at 1746 (negative) and 1719 (positive) $\mathrm{cm}^{-1}$. The assignment of these two bands to the lactonic $\mathrm{C}=\mathrm{O}$ of Per in (respectively) its fundamental $S_{0}$ and triplet $T_{1}$ state is based on: (1) comparison with FTIR spectra of isolated Per in literature; (2) good agreement with DFT calculations for Per and ${ }^{3}$ Per; (3) the downshift of the band upon triplet formation as predicted by DFT calculations in Per and similar lactonic systems; (4) the kinetic of band disappearance, in agreement with literature data. Another possible band for Per in its fundamental state has been identified at $1523 \mathrm{~cm}^{-1}$.

The results are in overall agreement with a recent step-scan FTIR study on PCP at 298 K (Alexandre et al., Biophys. J. 93 (2007), 2118-2128) even though some small discrepancies emerge, probably related to the different temperature at which experiments were carried out. Further DFT calculations have been performed to rationalise these spectral discrepancies. From a methodological point of view, the work demonstrates the potential of a combined step-scan FTIR/DFT approach in the study of photophysical processes in proteins. Furthermore, it has been shown that, when small differential IR signals are concerned, nagging photothermal effects can interfere and can possibly lead to misleading interpretations.
\end{abstract}

Keywords: Step-scan FTIR, DFT, triplet state, peridinin, peridinin-chlorophyll- $a$-protein

\section{Introduction}

Light-harvesting $(\mathrm{LH})$ complexes are used by photosynthetic organisms to increase the overall efficiency of photosynthesis. This is accomplished by harvesting light energy and funnelling it to the reaction center (RC), where it is converted into electrochemical potential.

\footnotetext{
*Corresponding author: Alberto Mezzetti, Laboratoire de Spectrochimie Infrarouge et Raman UMR CNRS 8516, Université de Sciences et Technologies de Lille, Bat. C5, Cité Scientifique, 59655 Villeneuve d'Ascq, France. Tel.: +33 320436603 ; Fax: +33 3204369 55; E-mail: alberto.mezzetti@univ-lille1.fr.
} 


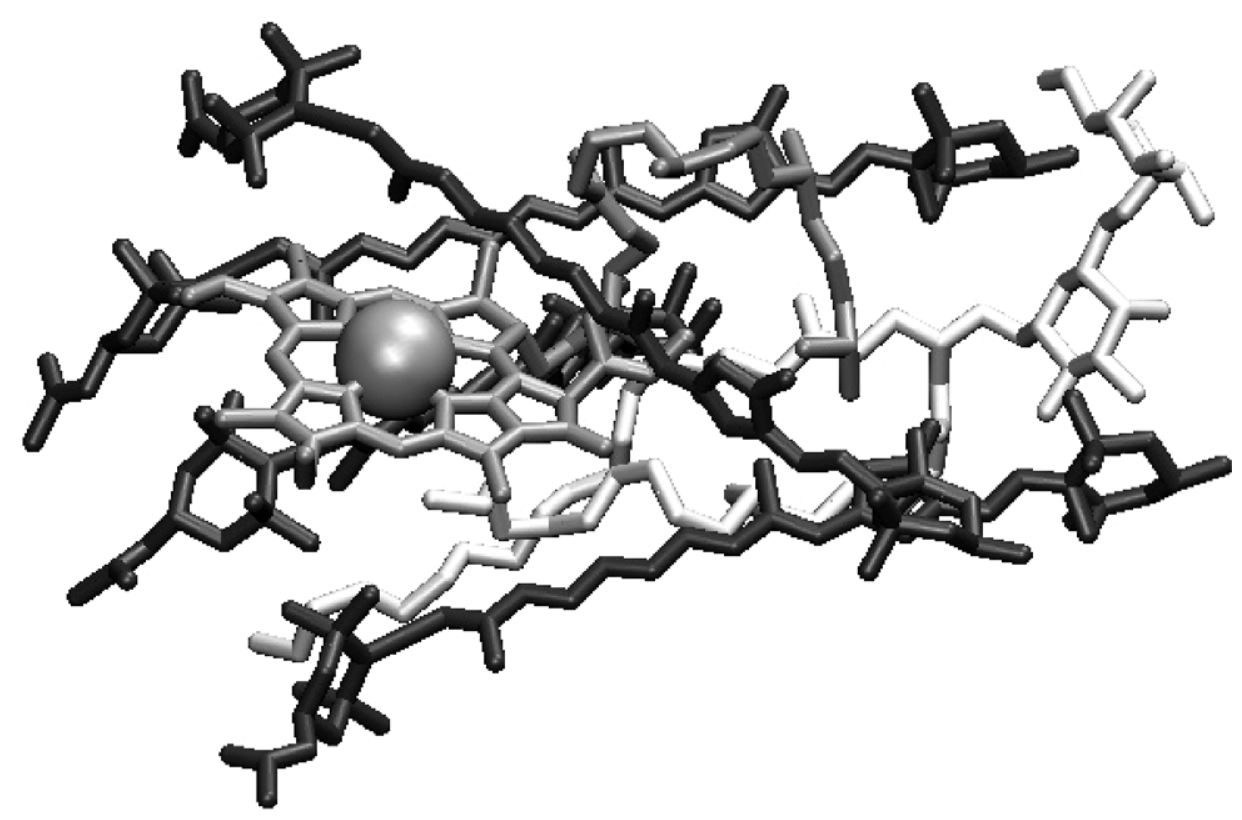

Fig. 1. Pigment and cofactors arrangement in PCP. Only one of the two units is shown for clarity. Per molecules are in dark grey, DGDG is light grey, and Chl- $a$ is in normal grey. The Mg atom is shown as a sphere.

Dinoflagellates are unicellular algae and constitute one of the most important classes of phytoplankton. The RCs of their photosynthetic apparatus (PSI and PSII) are identical to those of all oxygenic organisms; however, they possess a very peculiar LH system which differs significantly from higher plants. In particular, dinoflagellates use a water-soluble LH complex called peridinin-chlorophyll- $a$-protein (PCP). PCP is the LH protein with a 4:1 carotenoid/chlorophyll ratio: more precisely, four peridinins (Per) per chlorophyll- $a$ (Chl- $a$ ). The structure of PCP from Amphidinium carterae has been solved by X-ray crystallography to a resolution of $2.0 \AA$ [1] and reveals a trimeric arrangement.

Monomeric PCP from A. carterae contains two Chl- $a$ and eight Per. These pigments are organized in two essentially similar units, each containing one Chl- $a$ and four Per. Each Per is in van der Waals contact with the tetrapyrrole ring of Chl- $a$ of the same unit [1] (see Fig. 1).

The presence of peridinin enables the organism to collect light in the $470-550 \mathrm{~nm}$ region where chlorophyll does not absorb [2,3]. In general, the photophysical properties of carotenoids are determined by their structure, essentially by the length of the $\pi$-electron system and the nature of the functional groups attached to the polyene chain [4,5]. Instead of the $\mathrm{C}_{40}$ system present in most carotenoids, Per has an unusual $\mathrm{C}_{37}$ skeleton (Fig. 2). The structure of Per is constituted by an allene moiety and a lactone ring which are conjugated with the $\pi$-electron system of the carotenoid backbone, an ester group located on one $\beta$-ring with a tertiary alcoholic group, and an epoxy group with a secondary alcohol on the opposite $\beta$-ring.

When light is absorbed by Per, excitation energy transfer to Chl- $a$ takes place with a very high efficiency $(\sim 90 \%)[2,6,7]$. This efficiency is achieved by the tight packing of the pigments, which minimizes the distance between the donor Per and the acceptor Chl- $a$.

Beside light harvesting, Per has also an important photoprotective role, as it can quickly and efficiently (100\%) quench, by energy transfer, the ${ }^{3} \mathrm{Chl}-a$ state which would otherwise be long-lived and a possible source of singlet oxygen $[6,8]$. Indeed, carotenoids generally serve, in photosynthetic systems, 


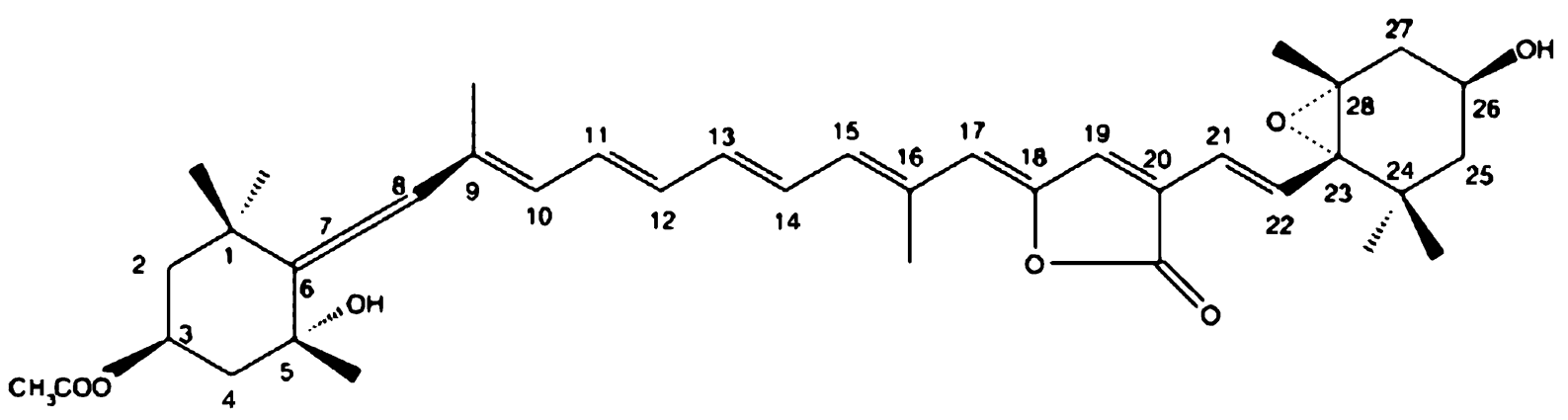

Fig. 2. Structural formula of peridinin.

as quenchers of long-lived chlorophyll triplet states (see [9-13] and references therein); they can also act by directly scavenging singlet oxygen $[13,14]$. It is important to mention that carotenoids play a photo-protective role also in human skin [15,16] and more generally an anti-oxidant role (see [17] and references therein) and possibly a correlated anti-cancer role (see [18] and references therein) in biology and medicine.

In isolated PCP complexes, where energy transfer to the RC cannot take place, the energy transfer scheme is the following: light is absorbed by Per or Chl- $a$, leading by direct excitation or energy transfer to the formation of ${ }^{1} \mathrm{Chl}-a^{*}[6,8,20]$. Then, the triplet state of Chl- $a$ is formed trough intersystem crossing. The Per triplet states are finally populated by triplet excitation energy transfer, which is governed by an electron exchange interaction [21]. The ${ }^{3}$ Per lifetime is in the range of some tenths of $\mu$ s according to the temperature $[6,8,22]$. Four conformers seem to be involved in triplet state formation [8] consistently with the observation of a bi-exponential decay at $77 \mathrm{~K}[8]$.

Light-induced infrared (IR) difference spectroscopy is a well-established technique which has been successfully used to investigate photophysical phenomena and photochemical reactions taking place in photosynthetic RC (see [23-26] and references therein) and LH complexes [27,28]. The technique allows reaction-induced changes in both the protein and the cofactors to be monitored (for a recent review see [29]). In particular, the technique has been used to investigate triplet-state formation in several photosynthetic RCs (see [24,30-32] and references therein).

Time-resolved IR difference spectroscopy (see [33] for a recent review) can be even more powerful, not only because it can follow the ongoing photosynthetic reaction under investigation (see $[34,35]$ and references therein), but also because it can give spectra of transient states [30,34,36-38].

Several time-resolved IR difference spectroscopy investigations have been carried out on triplet formation in photosynthetic proteins $[27,30,31,36]$. Given the short lifetimes of triplet states, only timeresolved technique with high ( $\mu$ s to ns) time resolution such as dispersive time-resolved IR spectroscopy [31] or time-resolved step-scan FTIR spectroscopy [27,30,36], have been applied. The latter technique is nowadays widely used; nevertheless, a thorough setting of experimental conditions and signal treatment is mandatory [39-43] to avoid spectral/temporal artefacts and minimize noise effects.

In both static and time-resolved IR difference spectra band assignment remains a difficult task; in particular, in the IR difference spectrum corresponding to the triplet formation of a pigment the bands observed in the carbonyl region (which is usually the most informative) can arise either from pigment vibrations or from protein vibrations (amide I band and/or amino acid side chains and/or other cofactors). The first and most obvious step towards band assignment is a direct comparison with the IR spectra of the isolated pigment [29]. Unequivocal band assignment can, however, be achieved only with more sophisticated strategies, such as the use of isotopically-labelled pigment or proteins [24,29], comparison of spec- 
tra recorded in $\mathrm{D}_{2} \mathrm{O}$ and $\mathrm{H}_{2} \mathrm{O}$ [29], site-directed mutagenesis [29] or comparison of IR difference spectra of the proteic complex corresponding to different photophysical processes (e.g., ${ }^{3}$ Pigment/Pigment and Pigment ${ }^{\text {tx }} /$ Pigment IR spectra - the band arising from the Pigment in its resting state must coincide (see $[24,30]$ and references therein)). However, these sophisticated methodologies are often difficult to apply. In this framework, a great help can come from DFT calculations of vibrational frequencies of pigments (both in the fundamental, resting state and in the triplet state).

In this paper, we have applied the step-scan FTIR difference spectroscopy in association with DFT calculations to investigate the process of ${ }^{3} \mathrm{Per}$ formation in isolated PCP complexes at low temperature $(100 \mathrm{~K})$. The results show the downshift of the lactonic $\mathrm{C}=\mathrm{O}$ of Per upon triplet formation; the signal has very similar kinetics to those reported in the literature [8].

A similar step-scan FTIR difference spectroscopy study of PCP has appeared very recently [27]. In that case experiments were carried out at room temperature using three different excitation wavelengths and an advanced method of time-resolved spectral data treatment, but no molecular quantum mechanics calculations were provided to support the spectral interpretation. In addition, despite an overall agreement in spectral shape and band assignment, some small but significant differences between the two studies, emerge, possibly related to the different temperature at which the measurements were carried out. The similarities and differences between the two studies are discussed in detail and rationalised by further DFT calculations.

\section{Materials and methods}

PCP samples from A. carterae were a kind gift from Prof. R.G. Hiller, Macquarie University, Australia. They prepared and purified as described in [44]. Samples were centrifuged (110,000 rpm) during 50 min and then concentrated on $\mathrm{aaF}_{2}$ window. The resulting paste was squeezed between two $\mathrm{CaF}_{2}$ windows.

Step-scan FTIR experiments were performed following the approach of Siebert [45] as previously described [30,46]. Briefly, a Bruker IFS 88 spectrometer equipped with Opus 3.0 software and a MCT-A photoconductive detector (Judson type J15D16) was used. The spectral range was set to 1974$1100 \mathrm{~cm}^{-1}$ using appropriate filters (LOT-Oriel). The pulse from a Nd:YAG laser Quantel 780:50 was used to trigger the reaction; the repetition rate was set to $4 \mathrm{~Hz}$. Single-sided interferograms were collected with $4 \mathrm{~cm}^{-1}$ resolution, corresponding to 570 mirror positions. Experiments were repeated using two different laser powers (1.5 and $3 \mathrm{~mJ})$. The $200 \mathrm{kHz}$ 16-bit analog-to-digital converter of the spectrometer was used. As this digitizer does not allow simultaneous recording of AC and DC components, a DC-coupled step-scan run was conducted first without excitation of the sample. In this way it was possible to obtain the single beam spectrum of the sample before excitation as well as a phase spectrum. Then an AC-coupled step-scan run was conducted, using the maximal signal gain possible (128) to increase the dynamic range of the transient signal, which however did not exceed $\sim 80 \mathrm{mV}$. In order to increase the signal-to-noise ratio, 20 traces were collected and averaged at each mirror position during the AC-session. The duration of such a cycle of measurement was $\sim 40 \mathrm{~min}$. For the $3 \mathrm{~mJ}$ laser power experiments results from 40 different cycles (obtained on three different samples) were averaged; for the $1.5 \mathrm{~mJ}$ laser power experiments, results from 20 different cycles were averaged.

The re-constructed delta-interferograms were Fourier-transformed using the phase obtained from the previous DC run (the phase did not change between DC and AC measurements because the movable mirror stopped at exactly the same mirror positions) and the Blackman-Harris-3-term apodization function. 
Absorbance difference spectra with a time resolution of $10 \mu$ s were calculated according to the formula $\Delta A=-\log ((S+\Delta S) / S$ ), where $S$ stands for the static single beam spectrum (Fourier transform of the DC-coupled interferogram) and $\Delta S$ the laser induced single beam difference spectrum (Fourier transform of the AC-coupled interferogram). Spectra were averaged over temporal windows in order to increase the signal-to-noise ratio (see captions of figures for further details).

DFT calculations where performed on peridinin using the B3LYP functional [47-49] with the 6-31G basis set at singlet and triplet spin states. Note that B3LYP functional was previously found by one of the authors to minimize X-ray structures with small deviations especially on the skeletal part [50] - even if at that time the basis set was smaller (3-21G). Hydrogen atoms were added to X-ray structures and local geometry optimizations were performed. On each optimized geometry, frequency calculations were performed, obtaining in all cases real frequencies, confirming us that a local energy minimum is obtained. To confirm results obtained with a relatively small basis set - that is a huge basis set for the dimension of peridinin - we have performed the same calculations on two model reduced systems (MRSs): the first one has the same peridinin skeleton but with terminal rings removed; the second one correspond to the lactonic ring bound to two $\mathrm{C}=\mathrm{C}$ double bonds, i.e. $2(5 \mathrm{H})$-furanone, 3-ethenyl-5-methylene. On these two systems we have performed geometry optimization and vibrational analysis using an extended basis set such as $6-311 \mathrm{G}(d, p)$. For $2(5 \mathrm{H})$-furanone, 3-ethenyl-5-methylene calculations were also performed adding a water molecule in an hydrogen-bond interaction with the lactonic $\mathrm{C}=\mathrm{O}$ (see Section 4). Frequencies are reported without any scaling factor, except when explicitly stated in the text. This is due to different considerations: (i) here DFT calculations are basically used to assign frequencies to vibrational modes, (ii) as it will be marked in next sections, the differences between un-scaled DFT and experimental vibrations are relatively small, especially for $\mathrm{C}=\mathrm{O}$ vibrations; (iii) scaling factors are calculated for molecules much smaller than peridinin and they take into account effects (in particular anarmonicity) that are largely dependent on the molecular size and shape; (iv) scaling factors are generally calculated for singlet states, and here the most important aspect is to identify the difference between singlet and triplet states. Thus, it seemed for us more appropriate to give in the tables the values directly obtained from B3LYP calculations and compare them to the experimental values.

\section{Results}

The first attempt was to record a FTIR difference spectrum under photo-accumulation conditions using a lamp, as in previous papers (see [24] and references therein). The attempt did not succeed, most probably for the short lifetime of the triplet state or an insufficient power of the used lamp. We, therefore, switched to step-scan FTIR difference spectroscopy.

In Fig. 3 two step-scan FTIR difference spectra in the $1900-1500 \mathrm{~cm}^{-1}$ region obtained $20 \mu$ s after the actinic event are shown at two different laser power ( 3 and $1.5 \mathrm{~mJ}$ ). Despite the quite low signal-to-noise ratio, ${ }^{1}$ which is a direct consequence of the very low signal, ${ }^{2}$ some spectral features clearly appear. In particular, both spectra show negative peaks (bleaching) at 1746, 1617, $1563-1565$ and $1523 \mathrm{~cm}^{-1}$ and positive peaks at $1766, \sim 1719,1663, \sim 1541, \sim 1533$, and $1513 \mathrm{~cm}^{-1}$. In the following, positive bands will be indicated by the $(+)$ symbol, whereas negative bands will be indicated by $(-)$. A first interesting

\footnotetext{
${ }^{1}$ The noise level can be assessed in the $1900-1800 \mathrm{~cm}^{-1}$ region, where no spectral contribution are in principle expected.

${ }^{2}$ Compared to the most studied photobiological reactions (e.g., bacteriorhodopsin cycle or electron transfer in bacterial photosynthetic RCs), the size of the signal is 5-30 times smaller. A similar problem was also found for the step-scan FTIR study of triplet state of the primary donor from Chlorobium tepidum [30,46].
} 


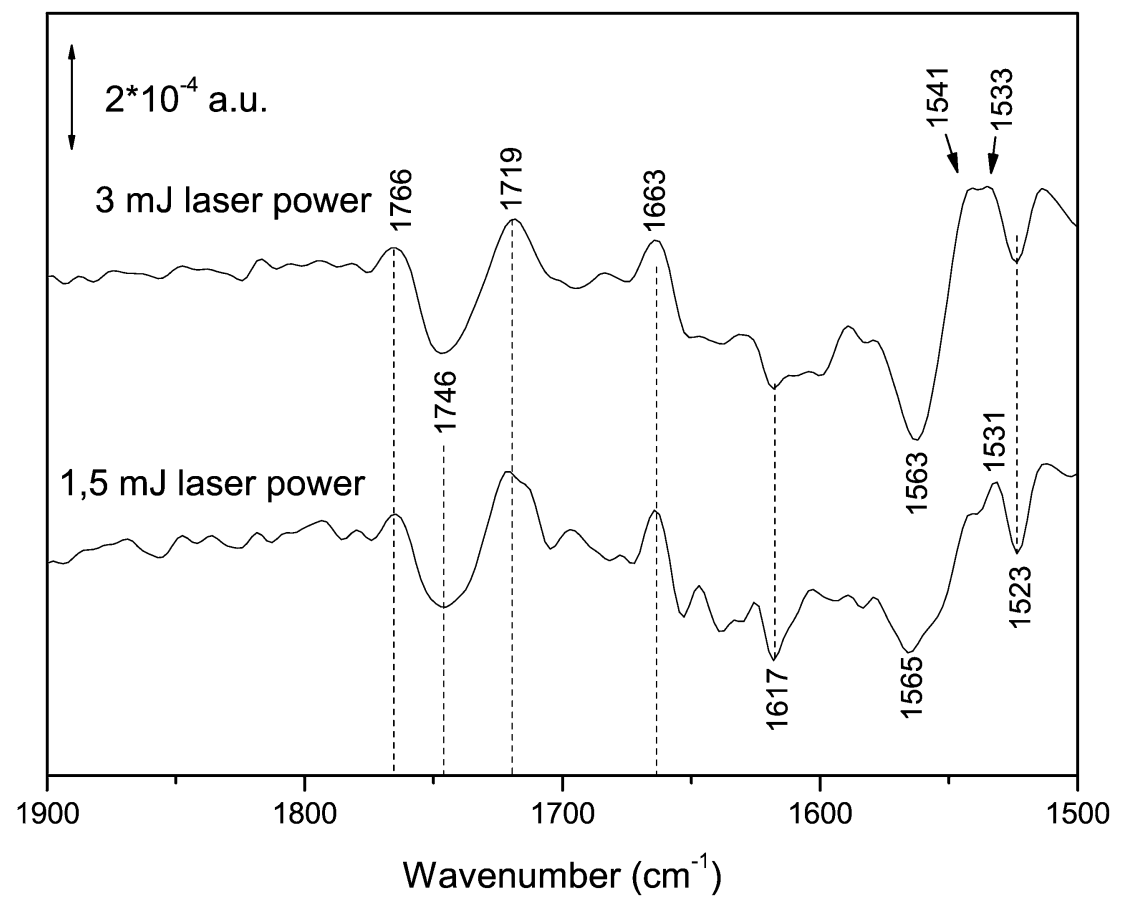

Fig. 3. Step-scan FTIR difference spectra recorded at $100 \mathrm{~K}$ at two different laser powers. In order to increase the signal-to-noise ratio, the spectra shown are the average of spectra recorded in the $0-40 \mu$ s range.

point is that some of the bands show an intensity that clearly does not depend on the power of the laser beam (this is the case of the bands at $\left.1766(+), 1746(-), \sim 1719(+), 1663(+) \mathrm{cm}^{-1}\right)$, whereas the intensity of some other bands clearly depend on it (this is the case for the $\sim 1563-1565(-), \sim 1541(+)$, $\sim 1533$ ( $+\mathrm{cm}^{-1}$ bands). Also the kinetics of the two groups of bands is different $\left(T_{1 / 2}=35 \pm 7 \mu \mathrm{s}\right.$ for the first group, $T_{1 / 2}=15 \pm 5 \mu$ s for the second group).

Such aspect suggests that there are two different physical phenomena responsible for the spectral changes in the spectra: one is, at least under the reported conditions, independent on the laser power used whereas the second one depends on it (with the intensity of bands being roughly proportional to the power of the laser).

Indeed, a similar effect on a protein sample has been reported and investigated in some detail [41]. In the cited investigation the authors reported that a laser flash induced a strong variation mainly in the amide II region (at to lesser extent in the amide I region); by comparison with results obtained with static temperature difference spectra the authors in [41] were able to attribute these spectral changes to a laser-induced heating effect on the protein. Even though the sample considered is different (the authors in [41] used chromophore-modified bacteriorhodopsin) the similarity in the amide II region between the spectral features they reported and those observed in the present spectra is quite striking. Not only does the position of positive and negative bands look very similar, but the size of the signal $\left(\sim(4-8) \times 10^{-4}\right.$ a.u.) is also comparable.

The disappearance kinetics of these features is quite different in the two cases (around $15 \mu \mathrm{s}$ in our experiments, some hundreds of $\mu \mathrm{s}$ in [41]) but this can be easily explained by the difference in temperature at which the experiments were carried out ( $298 \mathrm{~K}$ in [41] vs. $100 \mathrm{~K}$ in the present study) as well by the different nature (bacteriorhodopsin vs. PCP) and conditions (e.g. hydration state) of the samples. 
In the spectra reported in Fig. 3, a strong indication that changes in the amide II band are induced by laser flash heating comes from their dependence upon laser power. The intensity of bands reflecting a pure photophysical or photochemical reaction shows a maximum (corresponding to the excitation of all available molecules). This does not hold for a pure laser-induced thermal heating effect: the higher the laser power, the stronger the heating effect and the higher the temperature jump induced on the sample. In conclusion, we interpret the strong differential feature in the $1565-1533 \mathrm{~cm}^{-1}$ region as a laser-induced thermal effect on the protein.

\subsection{Tentative band assignment for Per}

The process of triplet formation entails Per disappearance and ${ }^{3} \mathrm{Per}$ formation. Therefore, we expect that Per bands should contribute, as negative peaks, in the FTIR difference spectra of Fig. 2. Indeed, the peaks at $1746(-)$ and $1523(-) \mathrm{cm}^{-1}$ match very well with the reported spectra for isolated Per in [51-53]) (see Table 1). Concerning the $1523 \mathrm{~cm}^{-1}$ band, is worth mentioning that a band at very similar wavenumber $\left( \pm 4 \mathrm{~cm}^{-1}\right)$ was reported also in resonance Raman spectra obtained either in vivo on PCP samples from Pyrocystis lunula [54] and Gonyaulax polyedra [55] or in aqueous and methanol solutions of Per [54,55].

The agreement with DFT calculations is also good (see Table 1). It is important to emphasise that DFT calculations were performed using the Per conformations of the crystallographic structure of PCP (with local optimization as described in the Section 2).

In fact, we have compelling evidence that the $1746 \mathrm{~cm}^{-1}$ band corresponds to the lactonic $\mathrm{C}=\mathrm{O}$ stretching vibration as the DFT value from B3LYP/6-31G calculations, without any a posteriori rescaling, is in the $1759-1756 \mathrm{~cm}^{-1}$ range for all the Per molecules in PCP. Similarly for the other C=O group of Per (an ester carbonyl present on one of the terminal rings) DFT calculations give a signal at $1728 \mathrm{~cm}^{-1}$ with a smaller intensity. In our spectra we have just one intense negative band (the one at $1746 \mathrm{~cm}^{-1}$ ) in the $1760-1710 \mathrm{~cm}^{-1}$ region. It is however possible that bleaching of this $\mathrm{C}=\mathrm{O}$ ester stretching signal lies in this region but is hidden by the large differential $1746(-) / 1719(+) \mathrm{cm}^{-1}$ band.

The $1523 \mathrm{~cm}^{-1}$ band is given by the $\mathrm{C}=\mathrm{C}$ stretching of Per [51-53]. Here the agreement with the value obtained from B3LYP/6-31G calculations without any a posteriori rescaling (1580 or $1578 \mathrm{~cm}^{-1} \mathrm{de}-$ pending on the considered Per) is less satisfactory but still acceptable (we have to keep in mind that with a typical 0.962 scaling factor [56] the agreement would be perfect, giving a value of $1519-1520 \mathrm{~cm}^{-1}$ ).

Table 1

Frequencies for main Per IR marker bands in the $1900-1500 \mathrm{~cm}^{-1}$ region

\begin{tabular}{|c|c|c|c|c|c|c|}
\hline & $\begin{array}{l}\text { Per in PCP } \\
\text { (tentative as- } \\
\text { signments), } \\
\text { this work }\end{array}$ & $\begin{array}{c}\text { Per in PCP } \\
\text { (tentative } \\
\text { assignments), } \\
\text { Alexandre et al. [27] }\end{array}$ & $\begin{array}{c}\text { Isolated Per, } \\
\text { Pinto et al. } \\
\text { [52] }\end{array}$ & $\begin{array}{c}\text { Isolated Per, } \\
\text { Furuichi et al. } \\
\text { [53] }\end{array}$ & $\begin{array}{c}\text { Isolated Per, } \\
\text { Strain et al. } \\
\text { [51] }\end{array}$ & $\begin{array}{c}\text { DFT calculations, } \\
\text { This work; } \\
\text { not-scaled values }\end{array}$ \\
\hline $\begin{array}{l}\text { Lactonic } \\
\mathrm{C}=\mathrm{O}\end{array}$ & 1746 & $\begin{array}{c}1746,1741 \\
1720\end{array}$ & 1741 & $1738(?)$ & 1745 & 1759-1756 \\
\hline $\begin{array}{l}\text { Ester } \\
\mathrm{C}=\mathrm{O}\end{array}$ & $\begin{array}{c}\text { Not } \\
\text { determined }\end{array}$ & $\begin{array}{c}\text { Not } \\
\text { determined }\end{array}$ & $\begin{array}{c}\text { Not } \\
\text { determined }\end{array}$ & $1738(?)$ & $\begin{array}{c}\text { Not } \\
\text { determined }\end{array}$ & $1729-1721$ \\
\hline $\begin{array}{l}\text { Skeleton } \\
\mathrm{C}=\mathrm{C}\end{array}$ & 1523 & 1630,1555 & 1521 & 1524 & 1525 & $1580-1578$ \\
\hline
\end{tabular}

Values are in $\left(\mathrm{cm}^{-1}\right)$. 
However, given the high number of possible molecular vibrators in the protein complex, the simultaneous presence of two negative bands with a very similar wavenumber to Per vibrations cannot be taken as an absolute, definitive indication of Per negative marker bands in the spectra. In particular, the 1746 (-) $\mathrm{cm}^{-1}$ peak could reflect also perturbation in (1) some Glu or Asp side chain; (2) the $\mathrm{C}=\mathrm{O}$ groups of the two digalactosyldiacylglycerol (DGDG) molecules present in PCP [1]; (3) the so-called $10 \mathrm{a}$-ester $\mathrm{C}=\mathrm{O}$ of the two Chl- $a$ molecules. All these carbonyl groups are expected to absorb in the $1730-1760 \mathrm{~cm}^{-1}$ region [24,57-59].

The first and second hypotheses are unlikely, as triplet formation does not normally entail strong perturbations in the IR bands of the protein surrounding the pigment carrying the photophysical phenomenon $[24,30]$.

The third hypothesis could be in agreement with the observation that a ${ }^{3} \mathrm{Chl}-a$ state is somehow implicated in the process of triplet delocalization on the Pers $[8,60]$. However is unlikely that the 1746 $(-) \mathrm{cm}^{-1}$ band observed in the spectra in Fig. 3 is given only by the bleaching of the 10 a-ester $\mathrm{C}=\mathrm{O}$ band of Chl- $a$ (reflecting formation of a ${ }^{3} \mathrm{Chl}-a$ ), as triplet formation in Chl- $a$ normally gives a weak negative peak for 10a-ester $\mathrm{C}=\mathrm{O}$ in FTIR difference spectra [24] and is accompanied by a much stronger peak given by the 9-keto $\mathrm{C}=\mathrm{O}$ stretching in the $1700-1630 \mathrm{~cm}^{-1}$ region. Instead, the $1746(-) \mathrm{cm}^{-1}$ band is one of the more intense negative peaks observed in the whole $1900-1500 \mathrm{~cm}^{-1}$ range whereas negative peaks in the $1700-1630 \mathrm{~cm}^{-1}$ region are weaker in intensity.

A strong support for the assignment of the $1746 \mathrm{~cm}^{-1}$ band to the lactonic $\mathrm{C}=\mathrm{O}$ stretching of Per comes from the DFT calculations on the effect of triplet formation, since the band changes position and shifts to lower wavenumbers (see Table 2) as observed experimentally. The calculated downshift for the four Per is also in good agreement with the presence of the $1719(+) \mathrm{cm}^{-1}$ band (see Table 2), which is therefore most probably due to the lactonic $\mathrm{C}=\mathrm{O}$ of ${ }^{3} \mathrm{Per}$. A final piece of evidence which favours the identification of the whole $1746(-) / 1719(+) \mathrm{cm}^{-1}$ differential feature as resulting from ${ }^{3} \mathrm{Per}$ formation comes from the kinetics of its decay $\left(T_{1 / 2}=35 \pm 7 \mu \mathrm{s}\right)$ in good agreement with the literature data coming from other techniques [8,22]. Our kinetic fitting does not show evidence for a bi-exponential decay as observed previously $[8,22]$; it should however be noted that the time-resolution of our instrument is limited to $10 \mu$ s (given by the preamplifier of the MCT detector) so that there were insufficient points for any detailed kinetic analysis.

Table 2

DFT calculations on the effect of triplet formation on Per and in model reduced systems

\begin{tabular}{lccccccc}
\hline & Per PID-611 & Per PID-612 & Per PID-613 & Per PID-614 & $\begin{array}{c}\text { Reduced } \\
\text { system 1 }\end{array}$ & $\begin{array}{c}\text { Reduced } \\
\text { system 2 } \\
\text { no H-bond }\end{array}$ & $\begin{array}{c}\text { Reduced } \\
\text { system 2 } \\
\text { with H-bond }\end{array}$ \\
\hline $\begin{array}{l}\text { Lactonic } \\
\mathrm{C}=\mathrm{O}\end{array}$ & $1759|\mathrm{~S}\rangle(\mathrm{h})$ & $1756|\mathrm{~S}\rangle(\mathrm{h})$ & $1756|\mathrm{~S}\rangle(\mathrm{h})$ & $1756|\mathrm{~S}\rangle(\mathrm{h})$ & $1836|\mathrm{~S}\rangle(\mathrm{h})$ & $1832|\mathrm{~S}\rangle$ & $1803|\mathrm{~S}\rangle$ \\
& & & & & & & $175|\mathrm{~T}\rangle$ \\
Ester & $1715|\mathrm{~T}\rangle(\mathrm{h})$ & $1715|\mathrm{~T}\rangle(\mathrm{h})$ & $1713|\mathrm{~T}\rangle(\mathrm{h})$ & $1715|\mathrm{~T}\rangle(\mathrm{h})$ & $1798|\mathrm{~T}\rangle(\mathrm{h})$ & $1770|\mathrm{~T}\rangle$ & $1750|\mathrm{~T}\rangle$ \\
$\mathrm{C}=\mathrm{O}$ & $1729|\mathrm{~S}\rangle(\mathrm{m})$ & $1721|\mathrm{~S}\rangle(\mathrm{m})$ & $1725|\mathrm{~S}\rangle(\mathrm{m})$ & $1721|\mathrm{~S}\rangle(\mathrm{m})$ & - & - & - \\
& $1725|\mathrm{~T}\rangle(\mathrm{h})$ & $1721|\mathrm{~T}\rangle(\mathrm{h})$ & $1725|\mathrm{~T}\rangle(\mathrm{h})$ & $1721|\mathrm{~T}\rangle(\mathrm{h})$ & - & - & - \\
\hline
\end{tabular}

$|\mathrm{S}\rangle$ means fundamental singlet state; $|\mathrm{T}\rangle$ means triplet excited state. (h) Means high intensity; (m) means medium intensity. Values are in $\left(\mathrm{cm}^{-1}\right)$ and not-scaled. See text for more details on the computational procedure. Reduced system 1: the same skeleton of Per but with terminal rings removed. Reduced system 2: the same lactonic ring of Per bound to two $\mathrm{C}=\mathrm{C}$ double bonds, i.e. 2(5H)-furanone, 3-ethenyl-5-methylene. 
On the basis of DFT calculations it is difficult to identify other $\mathrm{C}=\mathrm{O}$ bands in the $1800-1700 \mathrm{~cm}^{-1}$ region which could belong to ${ }^{3}$ Per: The ester $\mathrm{C}=\mathrm{O}$ stretching does not appreciably shift from the position of the fundamental singlet as expected, since this $\mathrm{C}=\mathrm{O}$ is not directly involved in the $\pi$ network of Per (see Table 2). It is probable that any downshift of this $\mathrm{C}=\mathrm{O}$ stretching, is too limited to be visible in the experimental spectra.

\subsection{Tentative band assignment for protein and Chl-a contributions}

In both spectra shown in Fig. 2, a small positive band is visible at $1766 \mathrm{~cm}^{-1}$. Comparison with IR literature data [51-53] and DFT calculations do not favour its attribution to a Per $\mathrm{C}=\mathrm{O}$ stretching mode (see also Table 1). This band could possibly be given by the side chain of an Asp or Glu residue [57], as suggested previously [27]. It is unlikely that such effect is given by a photothermal effect as its intensity remains the same in both spectra shown in Fig. 3.

Apart from the laser pulse-heating effect described above, no clear protein backbone contribution can be identified with certainty in the amide II region $\left(\sim 1550 \mathrm{~cm}^{-1}\right)$. This may be due to the interference given by the bands reflecting the laser pulse-heating effect as well as by the relatively poor signal-tonoise ratio of the spectrum.

In the amide I region $\left(1690-1620 \mathrm{~cm}^{-1}\right)$, a positive band is visible at $1663 \mathrm{~cm}^{-1}$ and its intensity is independent on the laser power; therefore, we attribute it to a pure photophysical (and not photothermal) effect. The band lies on a typical region for 9-keto $\mathrm{C}=\mathrm{O}$ stretching of ${ }^{3} \mathrm{Chl}-a$; on the other hand, this band could also be given by an amide I contribution reflecting a protein response to the triplet state formation in PCP. Previous studies on photosynthetic RCs have shown that triplet formation does not normally induce strong perturbations in the IR bands of the protein backbone [24,32]. However, given the peculiar photophysics of the triplet state in the PCP system [22], amide I (as well amide II) contributions reflecting protein changes cannot $a$ priori be excluded. It should also be kept in mind that in this region several amino acids side chains can also absorb [57]. Therefore, although the spectral position of the 1663 (+) band $\mathrm{cm}^{-1}$ would agree with its assignment to the 9-keto of ${ }^{3} \mathrm{Chl}-a$, there is no strong evidence pointing towards such an attribution.

\section{Discussion}

A recent step-scan FTIR investigation of the same system (with laser excitation at three different wavelength: 480, 530 and $670 \mathrm{~nm}$ ) has been recently reported in the literature [27]. The working temperature in that study was $298 \mathrm{~K}$. On the contrary, our spectra were recorded at $100 \mathrm{~K}$. Therefore, these two studies can be considered as complementary as they provide information of the mechanism of triplet formation in PCP complexes probed by time-resolved FTIR spectroscopy at two different temperatures. It is important to remember that a large amount of spectroscopic data on the process of triplet formation in PCP at different temperatures is coming from other techniques: steady-state UV-Vis; time-resolved UV-Vis; fluorescence; circular dichroism; optically detected magnetic resonance; electron spin resonance, electron nuclear double resonance (see $[8,22,61,62]$ and references therein).

A strong methodological difference between the two step-scan FTIR investigations is the treatment of the raw FTIR difference spectra: Alexandre at al. [27] analyzed their data by a global analysis approach that enabled them to calculate two spectra corresponding to two different components with different lifetime. In our case, we refrained from such analysis or any other chemometric treatment of the data because of the limited signal-to-noise ratio (consequence of both low signal and intrinsic limitations of 
the used spectrometer) and of the limited time resolution. So, the FTIR difference spectra we report are the raw ones, without any further data analysis or spectral treatment.

By comparing our spectra with the raw spectrum (prior to global analysis treatment) reported by Alexandre et al. [27] upon excitation at $530 \mathrm{~nm},{ }^{3}$ several common features appear. First of all in both cases the negative band we assigned to the lactonic $\mathrm{C}=\mathrm{O}$ of Per in its fundamental state $\left(1746 \mathrm{~cm}^{-1}\right)$ is present. Also the positive band at $1719 \mathrm{~cm}^{-1}$ we assigned to the same carbonyl moiety of ${ }^{3} \mathrm{Per}$ is present in both cases. The positive band we observe at $1766 \mathrm{~cm}^{-1}$ is downshifted, in their spectrum, to $1760 \mathrm{~cm}^{-1}$. Several other spectral features appear very similar: first of all, the strong differential signal at $\sim 1566(-) / \sim 1533(+) \mathrm{cm}^{-1}(1555(+) / 1530(-)$ in [27]) we attributed to a laser-induced thermal effect; also the $1523(-) \mathrm{cm}^{-1}$ and $1513(+) \mathrm{cm}^{-1}$ peaks seem to be present. The band we observe at $1663(+) \mathrm{cm}^{-1}$ is replaced by two strong bands at $1670(+)$ and $1657(+) \mathrm{cm}^{-1}$ in the spectra in [27].

It is important also to point out that the spectra obtained upon excitation at 670 and $480 \mathrm{~nm}$ in [27] compare pretty well with our spectra.

We can, therefore, conclude that, as far as the raw, untreated FTIR difference spectra are concerned, there is an overall agreement between the two works. The small differences observed (such as exact band position) can be ascribed to the different experimental conditions: first of all the temperature (298 vs. $100 \mathrm{~K}$ ) but also the intensity of the signal (and therefore the signal-to-noise ratio) or other effects such as, e.g., the hydration state of the samples.

The situation slightly changes when the two spectral components calculated in [27] and attributed to two different triplet states are considered. The presence of these two components is one of the main points of the paper of Alexandre et al. For this reason, in the following, we provide a detailed and critical comparison of our spectral data and our DFT calculations with the two different spectral components reported in [27]. The small discrepancies are discussed and possible explanations are provided.

\section{1. $1770-1700 \mathrm{~cm}^{-1}$ region}

In this region, one of the two spectral components calculated by Alexandre et al. [27] looks very similar to our spectra. In particular, the negative band at $1745 \mathrm{~cm}^{-1}$ matches almost perfectly the 1746 (-) $\mathrm{cm}^{-1}$ band present in our spectra; the same thing is observed for the positive band at $1720 \mathrm{~cm}^{-1}$ (in our case $1719 \mathrm{~cm}^{-1}$ ). As discussed above, the most convincing interpretation is that this band reflect a downshift of the lactonic $\mathrm{C}=\mathrm{O}$ of Per upon triplet formation. Also the positive peak at $1770 \mathrm{~cm}^{-1}$ compares pretty well with the $1766(+) \mathrm{cm}^{-1}$ band of our spectra; in both cases the peak has been tentatively assigned to an Asp or Glu side chain.

The second spectral component reported by Alexandre et al. [27], on the contrary, show negative bands at 1741 and $1720 \mathrm{~cm}^{-1}$ which were assigned to the lactonic $\mathrm{C}=\mathrm{O}$ of two different Per conformers. ${ }^{4}$ It is possible that such components are present - albeit hidden by the strong $1746(-)$ and $1719(+) \mathrm{cm}^{-1}$ bands - in our untreated spectra (where the two components, if present, are superposed). Therefore, we decided to perform some DFT calculations to explain the presence of two Per conformers with such different lactonic $\mathrm{C}=\mathrm{O}$ stretching wavenumber. We found that the $\mathrm{C}=\mathrm{O}$ stretching of a $\gamma$-lactonic system close to the one found for Per downshifts by $\sim 30 \mathrm{~cm}^{-1}$ upon interacting, as an acceptor, with a hydrogen bond donor (such as water) (see Table 2). Furthermore, the presence of the H-bond does not modify significantly the tendency of the lactonic $\mathrm{C}=\mathrm{O}$ stretching to downshift upon triplet formation; in

\footnotetext{
${ }^{3}$ We recall that our laser excitation was at $532 \mathrm{~nm}$.

${ }^{4}$ The positive bands corresponding to the same vibrations in the ${ }^{3}$ Per state were not determined in [27] for this second spectral component.
} 
other words, a bleaching of the lactonic $\mathrm{C}=\mathrm{O}$ for ground-state Per is to be expected also in the presence of the $\mathrm{H}$-bond interaction. Therefore the two negative peaks observed by Alexandre et al. in their second component could correspond to two Per conformers, one with its lactonic $\mathrm{C}=\mathrm{O}$ hydrogen-bonded to a donor molecule and the other to a "free" or very weakly hydrogen-bonded lactonic $\mathrm{C}=\mathrm{O}$. The crystal structure of PCP shows two possible hydrogen-bond donor for two of the eight Pers: more precisely, the oxygen of the lactonic $\mathrm{C}=\mathrm{O}$ of Per 623 is a $2.80 \mathrm{~A}$ from the oxygen atom of a trapped water molecule (the Per numbering is the one used in the protein data bank (pdb), entry code 1 PPR) [1]. Furthermore, Per 622 has the oxygen atom of its lactonic $\mathrm{C}=\mathrm{O}$ at $2.95 \AA$ from the nitrogen of the side chain of Asn 284 , even though the geometry does not seem to favour an H-bond. It should however be remembered that the structure in solution could in some details differ from the one in the crystal, especially concerning the presence of internal water molecules. Moreover, it should be mentioned that the local environment of the four Per in the protein is different and it is able to modify dynamical properties (and thus vibrational signature) of Per. Indeed, molecular dynamics simulations have shown that one Per for each cluster is much less mobile then the other three [63].

\section{2. $1700-1640 \mathrm{~cm}^{-1}$ region}

This spectral region appears particularly interesting as molecular vibrations of Chl- $a$ are expected to absorb in this region [24,59]. The presence of negative Chl- $a$ bands and, even more importantly, the presence of positive ${ }^{3} \mathrm{Chl}-a$ bands in this region would mean a significant involvement of the ${ }^{3} \mathrm{Chl}-a$ state in the triplet delocalization mechanism.

Alexandre et al. [27] identified in both their spectral components negative peaks at 1699 and $1686 \mathrm{~cm}^{-1}$, and assigned them to 9-keto $\mathrm{C}=\mathrm{O}$ stretching of the two Chl- $a$ molecules present in PCP. They identified the corresponding positive peaks of ${ }^{3} \mathrm{Chl}-a$ at 1670 and $1657 \mathrm{~cm}^{-1}$ respectively, in agreement with the general observation that Chl- $a$ triplet formation entails a downshift of the frequency of the 9-keto $\mathrm{C}=\mathrm{O}$ stretching [24]. Also the extent of the downshift is comparable with those reported in the literature (see [24] and references therein). In our spectra the negative bands at 1699 and $1686 \mathrm{~cm}^{-1}$ are not clearly visible; on the contrary, a strong positive band appears at $1663 \mathrm{~cm}^{-1}$, which could in principle correspond to the 1670 and/or $1657 \mathrm{~cm}^{-1}$ bands reported in [27]. The difference in the position between the two step-scan FTIR studies could be explained by the different temperature at which the experiments were carried out. Furthermore, it should also be kept in mind that in FTIR difference spectra of protein complexes the whole region around $\sim 1650 \mathrm{~cm}^{-1}$ is characterized by a noise level that is much more intense than in other regions.

An important point to put in evidence is the independence of the intensity of the band on laser power, which excludes its attribution to laser-induced heating effect on the amide I band.

However, given the huge number of possible vibrators present in PCP complexes that could possibly absorb in that region, we stress that the attribution of the $1663 \mathrm{~cm}^{-1}$ positive band present in our spectra to the 9-keto $\mathrm{C}=\mathrm{O}$ stretching of ${ }^{3} \mathrm{Chl}-a$ should be considered as tentative. For instance, the band could also be given by an amide I contribution reflecting a protein conformational change related to the triplet formation. A more precise assignment would require experiments on isotope-labelled samples or other strategies for band assignment $[24,29]$ as mentioned in the introduction.

\section{3. $1640-1500 \mathrm{~cm}^{-1}$ region}

This is the region where our spectra and the interpretation we give to them differs significantly from those reported by Alexandre et al. [27]. We recall that our interpretation is supported by direct compar- 
ison with IR spectra of Per from the literature [51-53] as well as by DFT calculations. Alexandre et al. [27] attribute the negative peaks at 1630 and $1555 \mathrm{~cm}^{-1}$ to the $\mathrm{C}=\mathrm{C}$ stretching of Per molecules. In our spectra, we have no clear indication of a $1630(-) \mathrm{cm}^{-1}$ peak; this discrepancy could however reflect the fact that this is the noisiest region of the FTIR spectra, or the difference in temperature between the two studies. Conversely, a negative peak close to $1555 \mathrm{~cm}^{-1}$ is indeed present (the position we observed is slightly upshifted to 1560 or $1566 \mathrm{~cm}^{-1}$ according to the laser power used). However, we have demonstrated that this negative band is most probably to be ascribed to a laser-induced heating effect of the amide II band.

The interpretation in [27] is also at odds with IR literature data for Per, that clearly show that the $\mathrm{C}=\mathrm{C}$ bond of Per absorbs in the $\sim 1521-1525 \mathrm{~cm}^{-1}$ region [51-53] and with our DFT calculations that predict a $\mathrm{C}=\mathrm{C}$ stretching band at around $1520 \mathrm{~cm}^{-1}$ after applying a typical scaling factor of 0.962 [56]. Indeed, Alexandre et al. did not consider the $\sim 1523(-) \mathrm{cm}^{-1}$ band that is clearly present in their spectra (both raw ones and calculated ones) upon $530 \mathrm{~nm}$ excitation [27]. Indications of this negative band are also present in the step-scan FTIR spectra they recorded following 670 and $480 \mathrm{~nm}$ excitation [27]. However, the deductions of Alexandre et al. still hold true even taking, as in our interpretation, the $1523(-) \mathrm{cm}^{-1}$ band (instead of the $1630(-)$ and the $1555(-) \mathrm{cm}^{-1}$ bands) as a marker for the $\mathrm{C}=\mathrm{C}$ vibrational mode of ground-state Per. Moreover, the bleaching of this band is consistent with a downshift of $\mathrm{C}=\mathrm{C}$ vibrations upon ${ }^{3} \mathrm{Per}$ formation as has also been observed for $\beta$-carotene, where the $S_{0} \rightarrow T_{1}$ transition induces a $\sim 20 \mathrm{~cm}^{-1}$ downshift of the $\mathrm{C}=\mathrm{C}$ stretching wavenumber [64].

\subsection{Photophysical model}

As stated previously, this step-scan FTIR investigation on triplet formation in PCP complexes carried out at $100 \mathrm{~K}$ is somehow complementary to the one carried out recently by Alexandre et al. on the same system but a room temperature [27].

As shown in the previous paragraphs, the present step-scan FTIR raw data seem to be in overall agreement with those reported by Alexandre et al. However, compared to the room temperature investigation [27], we have no data consistent with two spectral components involving different Per conformers. This could either be due to the lack of a detailed chemometric analysis of the spectra or to a modification of the global photophysical mechanism of triplet formation at low temperature, so that at $100 \mathrm{~K}$ only one of the two components identified by Alexandre et al. is populated.

In this framework, it should be noted that a very recent time-resolved EPR investigation [61] suggests that the triplet state is mainly localized on a specific Per molecule in each subcluster. Moreover, another very recent Q-band pulsed ENDOR study performed at low temperature $(80 \mathrm{~K})$ on a reconstituted PCP complex (so-called refolded PCP) [62] has confirmed that under these conditions the triplet is localized on one Per molecule per subcluster. These results acquire a special relevance given the selectivity of EPR techniques to paramagnetic states such as ${ }^{3} \mathrm{Per}\left(\operatorname{or}^{3} \mathrm{Chl}-a\right)$.

It is clear that an improvement in the temporal resolution as well as in the signal intensity of the step-scan FTIR difference spectra would permit an advanced analysis and to disentangle - if present the two or more components active in the mechanism of triplet formation. On the other hand, the DFT calculations have provided a possible explanation for the origin of the different Per conformers identified at room temperature in [27], i.e. the presence and/or the strength of an H-bond interaction involving the lactonic $\mathrm{C}=\mathrm{O}$ of the Per. Beside an obvious effect of IR band position, such interaction can possibly modulate the photophysical properties of the different Peridinins in PCP and could, therefore, be 
the molecular basis underlying the presence of the two triplet components identified at room temperature.

The second main point put forward by Alexandre et al. is the possible coexistence - at room temperature - of ${ }^{3} \mathrm{Chl}-a$ and ${ }^{3}$ Per vibrational modes, meaning that the triplet state formed in isolated PCP complexes involves both Chl- $a$ and Per molecules in PCP. Concerning this issue, despite the fact that we clearly see a positive band at $1663 \mathrm{~cm}^{-1}$ that could be given by ${ }^{3} \mathrm{Chl}-a$, we stress that no strong evidence for such an assignment exist in our spectra (i.e., at low temperature). Also the assignments made by Alexandre et al. for the room temperature FTIR spectra, which however rely on the simultaneous presence of several positive and negative bands compatible with the formation of ${ }^{3} \mathrm{Chl}-a$ state, should be considered as tentative. Indeed, it should be mentioned that time-resolved EPR experiments did not show spectral contributions arising from a ${ }^{3} \mathrm{Chl}-a$ state [61].

\section{Conclusions and perspectives}

In this paper we have successfully applied the step-scan FTIR technique to investigate the phenomenon of triplet formation in PCP complexes at low temperature. The spectra are in overall agreement with a recent step-scan FTIR work carried out at room temperature.

The comparison with literature data for IR spectra of isolated Per and with the IR spectra calculated by DFT methods has largely confirmed the assignments for Per bands after laser flash excitation. Definitive assignment will be however possible only by using PCP complexes reconstituted with isotopicallylabelled Per or, alternatively, by a direct comparison of ${ }^{3} \mathrm{Per} / \mathrm{Per}$ and $\mathrm{Per}^{+} / \mathrm{Per}$ FTIR difference spectra (see $[24,30,32]$ and references therein).

Although the presence of the $1663(+) \mathrm{cm}^{-1}$ band is in agreement with the possible presence of ${ }^{3} \mathrm{Chl}-a$, we do not have any strong evidence pointing towards a coexistence of ${ }^{3} \mathrm{Chl}-a$ and ${ }^{3} \mathrm{Per}$ state in the present conditions $(100 \mathrm{~K})$. More detailed and sophisticated step-scan FTIR difference experiments will be needed in order to clarify this issue.

From a methodological point of view, we have shown that extreme care should be taken when dealing with very small IR differential signals (in the order of $(2-4) \times 10^{-4}$ a.u.) in step-scan FTIR difference spectra, as an otherwise negligible laser-induced heating of the sample can lead to misleading interpretations on the spectra. In addition, we have shown that DFT calculations can rationalise spectral manifestations of triplet formation and hydrogen bonding interaction.

More generally, a detailed and complete characterization of the Per vibrational modes appears highly desirable also outside the framework of investigations of the photoprotective mechanisms of PCP. In fact, it has been demonstrated that with a microspectroscopic Resonance Raman approach Per can be visualized directly in vivo [54,55]. Indeed, Resonance Raman spectroscopy of carotenoids is already widely used to understand the light-harvesting dynamics in thylakoid membranes [65] but also as a noninvasive tool in Biomedical Optics [66]. Especially in this latter context, it is probable that Resonance Raman (micro-)spectroscopy will acquire an increasing biomedical interest as a tool to localize and identify Per molecule and possibly to get some information on its conformation and/or its environment. Indeed, very recent researches have pointed out a possible anti-cancer role of Per [67,68]; on the other hand, it is worth mentioning that PCP complexes are used as dyes for in analytical biochemistry since the beginning of the 90's (see [69]; for more recent developments and applications see also [70] and references therein). 


\section{Acknowledgements}

The authors thank Prof. M. Aschi and Prof. J.-C. Merlin for fruitful discussion, Prof. R.G. Hiller for the gift of PCP samples and careful reading of the manuscript, and Dr. W. Leibl for the use of the stepscan FTIR spectrometer and help in the measurements. A.M. wishes to thank Prof. G. Giacometti for the strong interest shown in this work and for having inspired the application of spectroscopic methods (including step-scan FTIR) to study PCP triplet photophysics.

A.M. acknowledges financial support from the "Angelo Della Riccia" Foundation, Florence, Italy and the "Ing. Aldo Gini" Foundation, Padova, Italy.

\section{References}

[1] E. Hofmann, P.M. Wrench, F.P. Sharples, R.G. Hiller, W. Welte and K. Diederichs, Structural basis of light harvesting by carotenoids: peridinin-chlorophyll-protein from, Amphidinium carterae, Science 272 (1996), 1788-1791.

[2] P.-S. Song, P. Koka, B.B. Prezelin and F.T. Haxo, Molecular topology of photosynthetic light-harvesting pigment complex, peridinin-chlorophyll- $a$-protein, from marine dinoflagellates, Biochemistry 15 (1976), 4422-4427.

[3] P. Koka and P.-S. Song, The chromophore topography and binding environment of peridinin-chlorophyll $a$-protein complexes from marine dinoflagellate algae, Biochim. Biophys. Acta - General Subjects 495 (1977), $220-231$.

[4] R.L. Christensen, The electronic states of carotenoids, in: The Photochemistry of Carotenoids, H.A. Frank, A.J. Young, M. Braun and R.J. Cogdell, eds, Kluwer, Dordrecht, The Netherlands, 1999, pp. 137-159.

[5] B.E. Kohler, Electronic structure of carotenoids, in: Carotenoids, Vol. 1B, Spectroscopy, G. Britton, S. Liaaen-Jensen and H. Pfanden, eds, Birkhäuser-Verlag, Basel, 1995, pp. 1-12.

[6] J.A. Bautista, R.G. Hiller, F.P. Sharples, D. Gosztola, M. Wasielewski and H.A. Frank, Singlet and triplet energy transfer in the peridinin-chlorophyll $a$ protein from Amphidinium carterae, J. Phys. Chem. A 103 (1999), 2267-2273.

[7] B.P. Krueger, S.S. Lampoura, I.H.M. van Stokkum, E. Papagiannakis, J.M. Salverda, C.C. Gradinaru, D. Rutkauskas, R.G. Hiller and R. van Grondelle, Energy transfer in the peridinin chlorophyll-a protein of Amphidinium carterae studied by polarized transient absorption and target analysis, Biophys. J. 80 (2001), 2843-2855.

[8] F.J. Kleima, M. Wendling, E. Hofmann, E.J.G. Peterman, R. van Grondelle and H. van Amerongen, Peridinin chlorophyll a protein: relating structure and steady-state spectroscopy, Biochemistry 39 (2000), 5184-5195.

[9] H.A. Frank and R.J. Cogdell, Carotenoids in photosynthesis, Photochem. Photobiol. 63 (1996), 257-264.

[10] N.J. Fraser, H. Hashimoto and R.J. Cogdell, Carotenoids and bacterial photosynthesis: The story so far. ., Photosynth. Res. 70 (2001), 249-256.

[11] B. Demmig-Adams, A.M. Gilmore and W.W. Adams 3rd, Carotenoids 3: in vivo function of carotenoids in higher plants, FASEB J. 10 (1996), 403-412.

[12] J. Penuelas and S. Munne-Bosch, Isoprenoids: an evolutionary pool for photoprotection, Trends Plant Sci. 10 (2005), $166-169$.

[13] R.J. Cogdell, T.D. Howard, R. Bittl, E. Scholodder, I. Geisenheimer and W. Lubitz, How carotenoids protect bacterial photosynthesis, Philos. T. Roy. Soc. B 355 (2000), 1345-1349.

[14] C.S. Foote, Y.C. Chang and R.W. Denny, Chemistry of singlet oxygen. X. Carotenoid quenching parallels biological protection, J. Am. Chem. Soc. 92 (1970), 5216-5218.

[15] W. Stahl and H. Sies, Carotenoids and flavonoids contribute to nutritional protection against skin damage from sunlight, Mol. Biotech. 37 (2007), 26-30.

[16] A.V. Anstey, Systemic photoprotection with alpha-tocopherol (vitamin E) and beta-carotene, Clin. Exp. Dermatol. 27 (2002), 170-176.

[17] W. Stahl and H. Sies, Antioxidant activity of carotenoids, Mol. Aspects Med. 24 (2003), 345-351.

[18] H. Nishino, Cancer prevention by carotenoids, Mutation Res. 402 (1998), 159-163.

[19] B.P. Krueger, S.S. Lampoura, I.H.M. van Stokkum, E. Papagiannakis, J.M. Salverda, C.C. Gradinaru, D. Rutkauskas, R.G. Hiller and R. van Grondelle, Energy transfer in the peridinin chlorophyll-a protein of Amphidinium carterae studied by polarized transient absorption and target analysis, Biophys. J. 80 (2001), 2843-2855.

[20] D. Zigmantas, R.G. Hiller, V. Sundström and T. Polivka, Carotenoid to chlorophyll energy transfer in the peridininchlorophylla-protein complex involves an intramolecular charge transfer state, Proc. Natl. Acad. Sci. USA 99 (2002), $16760-16765$.

[21] R.J. Cogdell and H.A. Frank, How carotenoids function in photosynthetic bacteria, Biochim. Biophys. Acta-Bioenergetics 895 (1987), 63-79. 
[22] D. Carbonera, G. Giacometti, U. Segre, A. Angerhofer and U. Gross, Model for triplet-triplet energy transfer in natural clusters of Peridinin molecules contained in Dinoflagellate's Outer antenna proteins, J. Phys. Chem. B 103 (1999), 63576362.

[23] J. Breton, J. Lavergne, M.C. Wakeham, E. Nabedryk and M.R. Jones, The unusually strong hydrogen bond between the carbonyl of $Q(A)$ and His M219 in the Rhodobacter sphaeroides reaction center is not essential for efficient electron transfer from $Q(A)(-)$ to $Q(B)$, Biochemistry 46 (2007), 6468-6476.

[24] J. Breton, Fourier transform infrared spectroscopy of primary electron donors in type I photosynthetic reaction centers, Biochim. Biophys. Acta - Bioenergetics 1507 (2001), 180-193.

[25] A. Remy and K. Gerwert, Coupling of light-induced electron transfer to proton uptake in photosynthesis, Nat. Struct. Biol. 10 (2003), 637-644.

[26] T. Noguchi, Light-induced FTIR difference spectroscopy as a powerful tool toward understanding the molecular mechanism of photosynthetic oxygen evolution, Photosynth. Res. 91 (2007), 59-69.

[27] M.T.A. Alexandre, D.C. Lührs, I.H.M. van Stokkum, R. Hiller, M.-L. Groot, J.T.M. Kennis and R. van Grondelle, Triplet state dynamics in peridinin-chlorophyll-a-protein: A new pathway of photoprotection in LHCs?, Biophys. J. 93 (2007), 2118-2128.

[28] H. Rogl, W. Kühlbrandt and A. Barth, Light-induced changes in the chemical bond structure of light-harvesting complex II probed by FTIR spectroscopy, Biochemistry 42 (2003), 10223-10228.

[29] A. Barth, Infrared spectroscopy of proteins, Biochim. Biophys. Acta-Bioenergetics 1767 (2007), 1073-1101.

[30] A. Mezzetti, D. Seo, W. Leibl, H. Sakurai and J. Breton, Time-resolved step-scan FTIR investigation on the primary donor of the reaction center from the green sulfur bacterium Chlorobium tepidum, Photosynth. Res. 75 (2003), 161-169.

[31] T. Noguchi, T. Tatsuya and K. Chihiro, Triplet formation on a monomeric chlorophyll in the photosystem II reaction center as studied by time-resolved infrared spectroscopy, Biochemistry 40 (2001), 2176-2185.

[32] E. Nabedryk, Light-induced Fourier trasform infrared difference spectroscopy of the primary electron donor in photosynthetic reaction centers, in: Infrared Spectroscopy of Biomolecules, H.H. Mantsch and D. Chapman, eds, Wiley-Liss, New York, 1996, pp. 39-81.

[33] C. Koetting and K. Gerwert, Proteins in action monitored by time-resolved FTIR spectroscopy, Chem. Phys. Chem. 6 (2005), 881-888.

[34] A. Mezzetti and W. Leibl, Investigation of ubiquinol formation in isolated photosynthetic reaction centers by rapid-scan FTIR spectroscopy, Eur. Biophys. J. 34 (2005), 921-936.

[35] S. Hermes, J.M. Stachnik, D. Onidas, A. Remy, E. Hofma and K. Gerwert, Proton uptake in the reaction center mutant L210DN from Rhodobacter sphaeroides via protonated water molecules, Biochemistry 45 (2006), 13741-13749.

[36] J.-R. Burie, W. Leibl, E. Nabedryk and J. Breton, Step-scan FT-IR spectroscopy of electron transfer in the photosynthetic bacterial reaction center, Appl. Spectrosc. 47 (1993), 1401-1404.

[37] A. Mezzetti, E. Nabedryk, J. Breton, M.Y. Okamura, M.L. Paddock, G. Giacometti and W. Leibl, Rapid-scan FTIR spectroscopy shows coupling of Glu-L212 protonation and electron transfer to $Q_{\mathrm{B}}$ in Rhodobacter sphaeroides reaction centers, Biochim. Biophys. Acta - Bioenergetics 1553 (2002), 320-330.

[38] L. Blanchet, A. Mezzetti, C. Ruckebusch, J.-P. Huvenne and A. de Juan, Multivariate curve resolution of rapid-scan FTIR difference spectra of quinone photoreduction in bacterial photosynthetic membranes, Anal. Bioanal. Chem. 387 (2007), $1863-1874$

[39] C. Rödig and F. Siebert, Error and artefacts in time-resolved step-scan FT-IR spectroscopy, Appl. Spectr. 53 (1999), $893-$ 901.

[40] C. Rödig and F. Siebert, Improvements in signal acquisition and processing for time-resolved step-scan FT-IR spectroscopy, in: Fourier Transform Spectroscopy: Eleventh International Conference, J. De Haseth, ed., American Institute of Physics, Woodbury, NY, 1998, pp. 388-391.

[41] C. Rödig, H. Georg, F. Siebert, I. Rousso and M. Sheves, Temperature effects of excitation laser pulses during step-scan FT-IR experiments, Laser Chem. 19 (1999), 169-172.

[42] C.J. Manning and P.R. Griffiths, Noise sources in step-scan FT-IR spectrometry, Appl. Spectrosc. 51 (1997), $1092-1101$.

[43] C. Rödig and F. Siebert, Instrumental aspects of time-resolved spectra generated using step-scan interometers, in: Handbook of Vibrational Spectroscopy, Vol. 2, J.M. Chalmers and P.R. Griffiths, eds, Wiley, 2002, pp. 641-654.

[44] K. Steck, T. Wacker, W. Welte, F.P. Sharples and R.G. Hiller, Crystallization and preliminary X-ray analysis of a peridininchlorophyll a protein from Amphidinium carterae, FEBS Lett. 268 (1990), 48-50.

[45] W. Uhmann, A. Becker, C. Taran and F. Siebert, Time-resolved FT-IR absorption spectroscopy using a step-scan interferometer, Appl. Spectr. 45 (1991), 390-397.

[46] A. Mezzetti, Time-resolved rapid-scan and step-scan FTIR difference spectroscopy: implementation of a versatile instrument and investigation of photosynthetic reaction centers, PhD dissertation, University of Padova, Italy, 2002.

[47] A.D. Becke, Density functional calculations of molecular bond energies, J. Chem. Phys. 84 (1986), 4524-4529.

[48] C. Lee, W. Yang and R.G. Parr, Development of the Colle-Salvetti correlation-energy formula into a functional of the electron density, Phys. Rev. B 37 (1988), 785-789. 
[49] A.D. Becke, Density-functional thermochemistry. III. The role of exact exchange, J. Chem. Phys. 98 (1993), 5648-5652.

[50] R. Spezia, C. Zazza, A. Palma, A. Amadei and M. Aschi, A DFT study of the low-lying singlet excited states of the all-trans peridinins in vacuo, J. Phys. Chem. A 108 (2004), 6763-6770.

[51] H.H. Strain, W.A. Svec, P. Wegfhaert, H. Rapoport, F.T. Haxo, S. Norgard, H. Kjøsen and S. Liaaen-Jensen, Algal carotenoids. XIV. Structural studies on peridinin. Part 1. Structure elucidation, Acta Chem. Scandin. B 30 (1976), 109-120.

[52] E. Pinto, L.H. Catalani, N. Peporine Lopes, P. Di Mascio and P. Colepicolo, Peridinin as the major biological carotenoid quencher of singlet oxygen in marinae algae Gonyaulax polyedra, Biochem. Biophys. Res. Comm. 268 (2000), 496-500.

[53] N. Furuichi, H. Hara, T. Osaki, M. Nakano, H. Mori and S. Katsumura, Stereocontrolled total synthesis of a polyfunctional carotenoid, peridinin, J. Org. Chem. 69 (2004), 7949-7959.

[54] A. Dupaix, B. Arrio, B. Lecuyer, C. Fresneau, J.-C. Merlin, P. Dhamelincourt and B. De Bettignies, Intracellular spectroscopic studies of a bioluminescent cell: Pyrocystis lunula, Biol. Cell 43 (1982), 157-162.

[55] J.C. Merlin, La microspectrométrie Raman de résonance: méthode d'investigation in vivo des systèmes pigmentaires, Spectrosc. Int. J. 2 (1983), 52-61.

[56] Computational Chemistry Comparison and Benchmark Database, NIST Standard Reference Database 101, Release 12, Aug 2005; http://srdata.nist.gov/cccbdb/.

[57] A. Barth, The infrared absorption of amino acid side chains, Prog. Biophys. Mol. Biol. 74 (2000), 141-173.

[58] A.V. Popova and D.K. Hincha, Intermolecular interactions in dry and rehydrated pure and mixed bilayers of phosphatidylcholine and digalactosyldiacylglycerol: a Fourier transform infrared spectroscopy study, Biophys. J. 85 (2003), 16821690 .

[59] M. Lutz and W. Mäntele, Vibrational spectroscopy of chlorophylls, in: Chlorophylls, H. Scheer, ed., CRC Press, Boca Raton, 1991, pp. 855-902.

[60] D. Carbonera, G. Giacometti and U. Segre, Carotenoid interactions in peridinin chlorophyll a proteins from dinoflagellates: evidence for optical excitons and triplet migration, J. Chem. Soc. Faraday Transactions 92 (1996), 989-993.

[61] M. Di Valentin, S. Ceola, E. Salvadori, G. Agostini and D. Carbonera, Identification by time-resolved EPR of the peridinins directly involved in chlorophyll triplet quenching in the peridinin-chlorophyll a-protein from Amphidinium carterae, Biochim. Biophys. Acta - Bioenergetics 1777 (2008), 186-195.

[62] J. Niklas, T. Schulte, S. Prakash, M. van Gastel, E. Hofmann and W. Lubitz, Spin-density of the carotenoid triplet state in the peridinin-chlorophyll-protein antenna. A Q-band pulsed electron-nuclear double resonance and density functional theory study, J. Am. Chem. Soc. 129 (2007), 15442-15443.

[63] R. Spezia, M. Aschi, A. Di Nola, M. Di Valentin, D. Carbonera and A. Amadei, The effect of protein conformational flexibility on the electronic properties of a chromophore, Biophys. J. 84 (2003), 2805-2813.

[64] H. Hashimoto, Y. Koyama, Y. Hirata and N. Mataga, S1 and T1 species of $\beta$-carotene generated by direct photo-excitation from the all-trans, 9-cis, 13-cis and 15-cis isomers as revealed by picosecond transient absorption and transient Raman spectroscopies, J. Phys. Chem. 95 (1991), 3072-3076.

[65] B. Robert, P. Horton, A.A. Pascal and A.V. Ruban, Insights into the molecular dynamics of plant light-harvesting proteins in vivo, Trends Plant Sci. 9 (2004), 385-390.

[66] I.V. Ermakov, M. Sharifzadeh, M. Ermakova and W. Gellermann, Resonance Raman detection of carotenoid antioxidants in living human tissue, J. Biomed. Opt. 10 (2005), 064028.

[67] T. Yoshida, T. Maoka, S.K. Das, K. Kanazawa, M. Horinaka, M. Wakada, Y. Satomi, H. Nishino and T Sakai, Halocynthiaxanthin and peridinin sensitize colon cancer cell lines to tumor necrosis factor-related apoptosis-inducing ligand, $\mathrm{Mol}$. Cancer Res. 5 (2007), 615-625.

[68] T. Sugawara, K. Yamashita, S. Sakai, A. Asai, A. Nagao, T. Shiraishi, I. Imai and T. Hirata, Induction of apoptosis in DLD-1 human colon cancer cells by peridinin isolated from the dinoflagellate, Heterocapsa triquetra, Biosci. Biotechnol. Biochem. 71 (2007), 1069-1072.

[69] F.F. Mandy, M. Bergeron, D. Recktenwald and C.A. Izaguirre, A simultaneous three-color T cell subsets analysis with single laser flow cytometers using $\mathrm{T}$ cell gating protocol. Comparison with conventional two-color immunophenotyping method, J. Immunol. Methods 156 (1992), 151-162.

[70] H. Niki, S. Hosokawa, K. Nagaike and T. Tagawa, A new immunofluorostaining method using red fluorescence of PerCP on formalin-fixed paraffin-embedded tissues, J. Immunol. Methods 293 (2004), 143-151. 


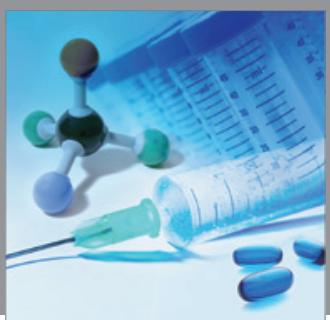

International Journal of

Medicinal Chemistry

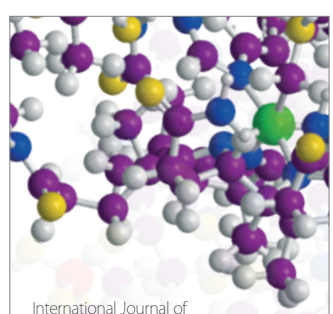

Carbohydrate Chemistry

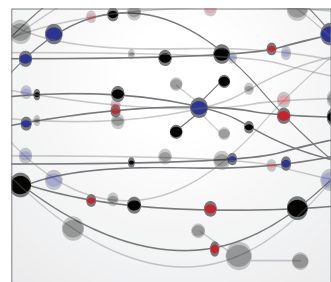

The Scientific World Journal
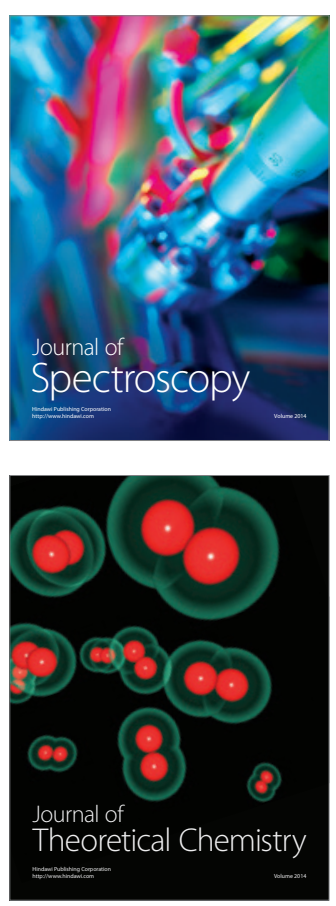
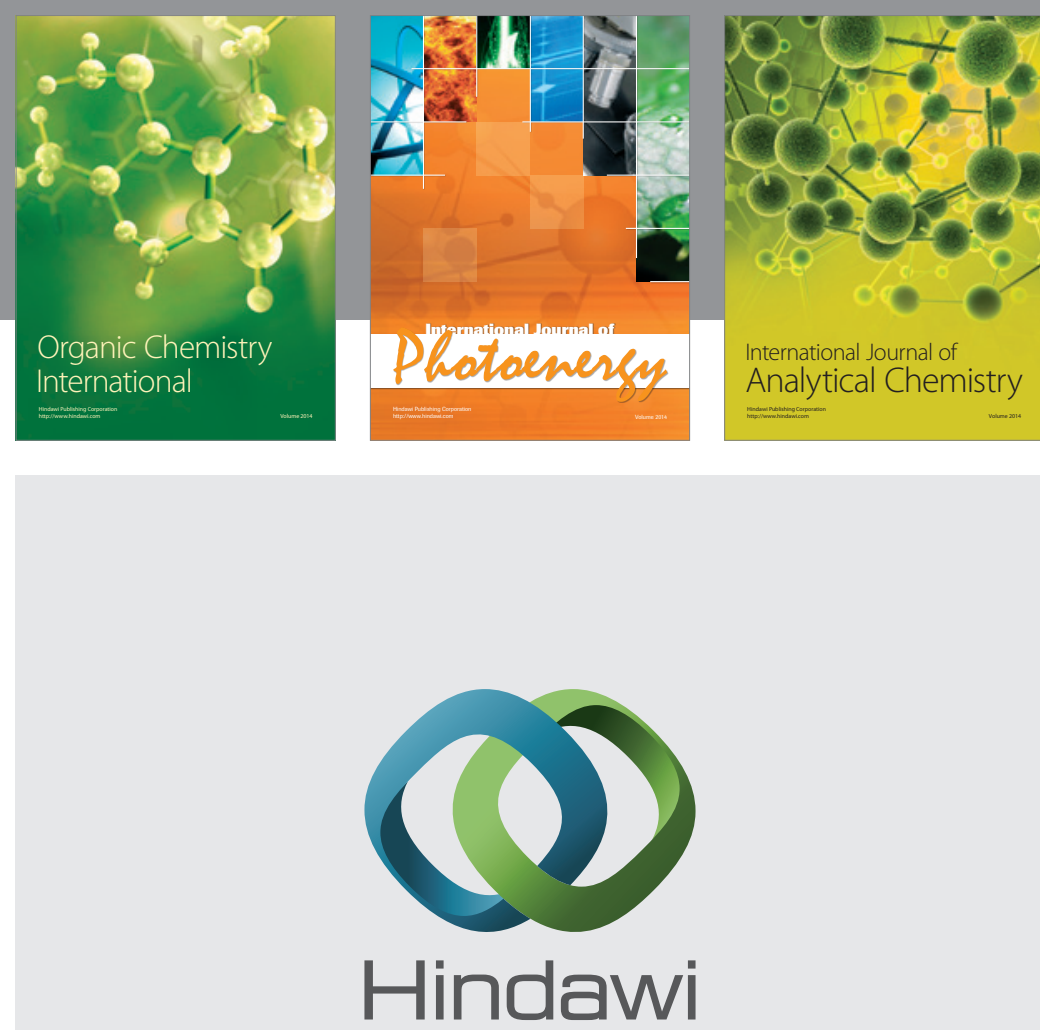

Submit your manuscripts at

http://www.hindawi.com
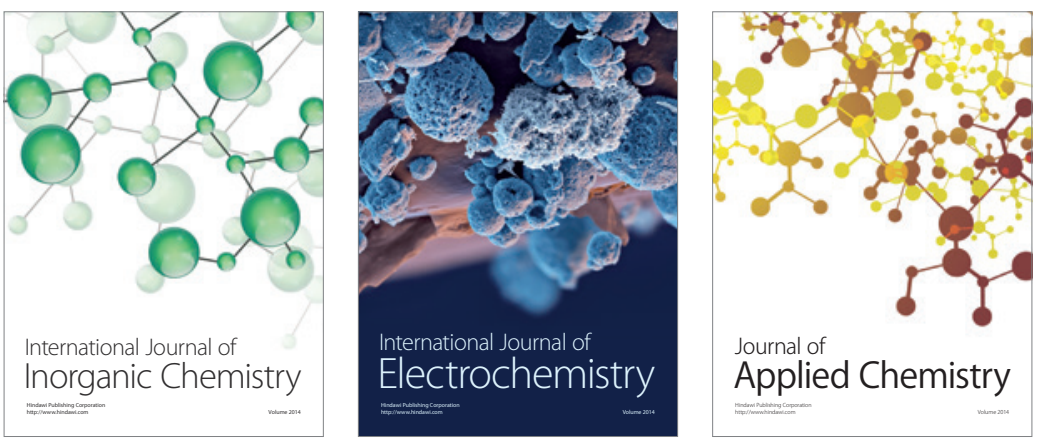

Journal of

Applied Chemistry
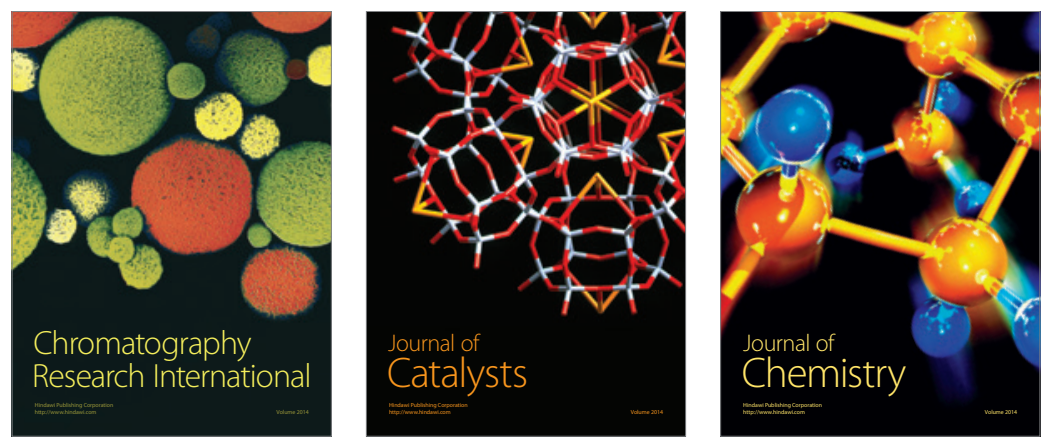
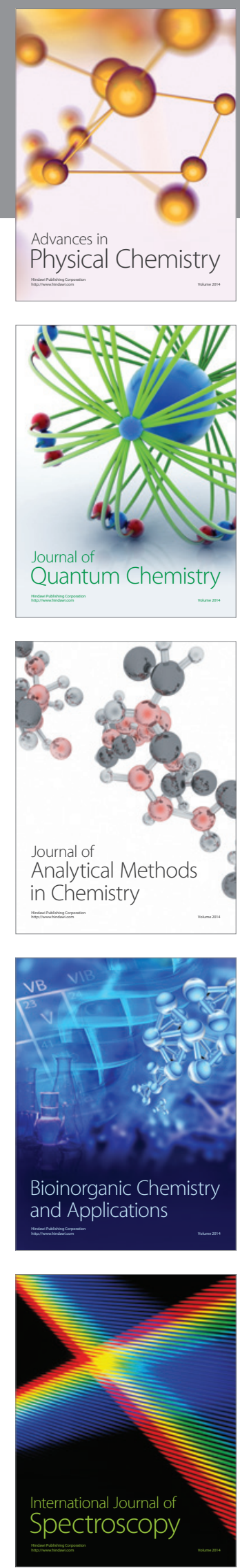